\title{
RAINER MARIA RILKE, POETA DE LO INVISIBLE. LA TRASCENDENCIA DE LA MUERTE EN LA OBRA TARDÍA DEL POETA: LAS ELEGÍAS DEL DUINO Y LOS SONETOS A ORFEO
}

\author{
María Olga Giménez Salinas \\ Universidad de Los Andes \\ Santiago- Chile \\ mgimenezsalinas@gmail.com
}

\section{RESUMEN / ABSTRACT}

El presente escrito propone una interpretación filosófico-literaria de la obra de Rainer Maria Rilke, realizada, fundamentalmente, a partir de Las elegías del Duino (1923) y los Sonetos a Orfeo (1923). Se plantea que la obra rilkeana contiene una propuesta de solución al problema existencial del hombre en el mundo, en el contexto de la crisis de la modernidad. El poeta describe una vía para lograr un 'nuevo arraigo' humano, cuyo eje fundamental es la aceptación de la muerte, que se concreta en la adquisición de conciencia respecto del propio cuerpo y su finitud, a partir de las vivencias sensibles.

Palabras Clave: trascendencia, muerte, invisible, poesía, existencia, ser humano, autoconciencia, experiencia, metafísica, ángel.

RAINER MARIA RILKE, POET OF THE INVISIBLE. THE TRANSCENDENCE OF DEATH IN THE LAST WORKS OF THE POET: DUINO ELEGIES AND SONNETS TO ORPHEUS

This paper proposes a philosophical-literary interpretation of the work of Rainer Maria Rilke, carried out, fundamentally, from: Duino Elegies (1923) and Sonnets to Orpheus (1923). It is suggested that the Rilkean work contains a proposal for a solution to the existential problem of man in the world, in the context of the crisis of modernity. The poet describes a way to achieve a new human root, whose fundamental axis is the acceptance of death, which is materialized in the acquisition of awareness of one's own body and its finitude, based on sensitive experiences.

KEYWORDS: transcendence, death, invisible, poetry, existence, human being, self-awareness, experience, metaphysics, angel. 


\section{I. - Introducción ${ }^{1}$}

'Todo pensamiento empieza con un poema' (...). Este inicio compartido, esta iniciación de mundos es difícil de suscitar. Sin embargo, deja huellas, ruidos de fondo compatibles con aquellos que susurran los origenes de nuestra galaxia. Sospecho que estas huellas se pueden discernir en el mysterium tremendum de la metáfora (Steiner 2012, p. 17).

$\overline{R A}$ La obra de Rilke ${ }^{2}$ ha despertado el interés de diversos filósofos desde el siglo XX hasta hoy, debido a la profundidad y el contenido de sus versos. En 'Y para qué poetas', Heidegger indaga sobre la relación entre el poetizar de Rilke y la penuria de los tiempos: ““... ¿y para qué poetas en tiempos de penuria?' La palabra 'tiempos' se refiere aquí a la era a la que nosotros mismos pertenecemos todavía (...) La era está determinada por la lejanía del dios, por la "falta de dios" (...). Pero en la falta de Dios se anuncia algo mucho peor. No solo han huido los Dioses y el Dios, sino que en la historia universal se ha apagado el esplendor de la divinidad. / (...) Ser poeta en tiempos de penuria significa: cantando, prestar atención al rastro de los Dioses huidos (...) ¿Es R. M. Rilke un poeta en tiempos de penuria? ¿Hasta dónde se acerca al abismo? (...). Los tiempos no son sólo de penuria por el hecho de que haya muerto Dios, sino porque los mortales ni siquiera conocen bien su propia mortalidad ni están capacitados para ello. Los mortales todavía no son dueños de su esencia. (...) Pero los mortales son. Son, en la medida en que hay lenguaje. Todavía se demora un canto sobre su tierra de penuria. La palabra del rapsoda preserva todavía la huella de lo sacro" (1996, pp. 199203). El mensaje rilkiano se dirige a recordar o redescubrir la esencia de lo humano.

Gadamer, coincidente con Heidegger, señala que "la poesía de Rilke está impregnada de la idea de que Dios está lejano. (...) nos advierte que debemos admitir y soportar erguidos esa lejanía. (...) La obra elegiaca alcanza su elevado nivel precisamente porque percibe y reconoce la infinita lejanía de Dios y porque intenta reprimir incluso la llamada al ángel" (1993, p. 72). La negación del poeta a aceptar cualquier consuelo de naturaleza sobrenatural frente al sentimiento de abandono y desarraigo producido a causa de la constatación de la lejanía de Dios, lo sitúa en un escenario literario nuevo en el contexto de la tradición romántica alemana, de la cual se nutre, pero la trasciende al intentar encontrar una salida a este sufrimiento: "Estamos, pues, ante una poesía de la lejanía de Dios. A esta lejanía se opone exactamente el elogio de "lo de aquí" (das Hiesige) y del "estar aquí" (das Hiersein), la apasionada confesión de la existencia terrenal, incluso en su extrema miseria, necesidad y acoso, opción que va unida al rechazo de la consolación en el más allá” (Ibid., pp. 72-73).

$1 \quad$ El artículo corresponde a la síntesis del trabajo de tesis presentado a la Facultad de Filosofía y Humanidades de la Universidad de Chile, para optar al grado de Magíster en Filosofía, enero 2016.

2 Praga, 1875 - Valmont, 1926. 
Sin embargo, aun cuando ambos filósofos -junto a otros estudiosos del poetacoinciden en identificar en él una actitud de aceptación de la realidad humana-diferente de la queja y el lamento-, que constituye el punto de partida para el aprendizaje acerca de la propia esencia, es necesario develar algunas claves para terminar de comprender el modo concreto mediante el cual se realiza la tarea de aceptación de la muerte que redundará en una transformación de la conciencia del yo. El presente escrito tiene como objetivo mostrar sucintamente y en forma orgánica los poemas que contienen las recomendaciones para el logro de dicho propósito. La obra de Rilke contiene numerosas sentencias acerca del modo de ser del hombre, que conforman una verdadera ascética conducente a la construcción de una identidad arraigada en lo inmaterial, que no esté reñida con la finitud. Pero es una ascética que contiene una paradoja: debido al vínculo entre la conciencia del propio cuerpo y la muerte, la 'transformación' ha de realizarse en el plano material, a partir de la experiencia sensible.

Rilke es un poeta de la trascendencia. El contenido central de su obra puede resumirse en lograr la entrada del yo al mundo de lo abierto, 'la otra realidad'. El registro de lo invisible -al que pertenecen el ángel, los dioses y los muertos-, contribuye a situar al lector al interior de ese plano, trasladando su mirada desde el aquende (mundo de la materia) hacia el allende (mundo abierto, sin límites temporales), promoviendo en él el recuerdo de algo que antes le fue cercano y que ahora ha olvidado: una realidad unitaria, que corresponde al 'espacio de la celebración' (Rilke 2002, p. 29). Aquí, el hombre realiza su misión: 'el canto sobre la tierra', a semejanza de Orfeo, cuyo canto procede de ambos reinos: vida y muerte, y otorga trascendencia al mundo circundante, incluyendo las cosas de uso diario, el propio cuerpo y la naturaleza.

A continuación, se definirán dos conceptos fundamentales para la comprensión de su mensaje poético: muerte y trascendencia. Luego, se expondrá su diagnóstico respecto de la situación existencial humana y, por último, se explicará su propuesta para concretar la aceptación de la muerte.

\section{II. - Desarrollo}

II.1.- Definición de conceptos clave: muerte y trascendencia

Muerte: Del latín mors, mortis: "cesación o término de la vida" y "en el pensamiento tradicional, separación del cuerpo y el alma"3. "Ampliamente entendida, la muerte es la designación de todo fenómeno en el que se produce una cesación”(Ferrater 1964, p. 238). Generalmente, el poeta utiliza el término muerte aludiendo a la primera significación descrita: la muerte que el hombre debe enfrentar y aceptar es precisamente la muerte de su cuerpo. Sin embargo, en algunas ocasiones el mismo término sirve para describir más bien un estado, un tiempo indefinido o un lugar colindante al mundo material.

Entrada: Muerte. En Diccionario de la Real Academia Española. Vigésima Segunda Edición. Versión en línea, disponible en: http://www.rae.es. 
Este uso del término no solo cuestiona la idea de muerte como fin de la vida, sino que sugiere la existencia de un principio inmaterial en el hombre.

Trascendencia: Del latín transcendentia: “"cualidad que está más allá de los límites naturales'. Sus componentes léxicos son: el prefijo trans- (de un lado a otro), scendere (trepar, escalar), -nt- (agente, el que hace la acción), más el sufijo -ia (cualidad)"4. Es un "significado espacial', es decir, 'ir de un lugar a otro, atravesando o traspasando cierto límite." (Ferrater, p. 828). Pero el término tiene otra dimensión, que coincide con más precisión con el uso del poeta: "Desde un punto de vista gnoseológico, hay también un trascender del sujeto, pero es hacia el objeto en tanto que objeto 'exterior' cognoscible. Se dice entonces que el objeto es trascendente al sujeto y que el sujeto puede alcanzarlo sólo cuando va 'hacia el objeto'. Así, la trascendencia gnoseológica del objeto presupone el trascender del sujeto hacia el objeto" (Ibid., p. 829). De este modo, en el contexto rilkiano, la trascendencia que el ser humano es capaz de realizar respecto de su propia muerte implica considerar, por un lado, a la muerte como un objeto 'cognoscible' y, por otro, la capacidad del sujeto de 'ir hacia' ella.

\section{II.2. Diagnóstico del poeta: el olvido de la muerte}

A pesar de las semejanzas entre la filosofía de Heidegger y la poesía de Rilke -“el propio Heidegger ha confesado una vez que su filosofía no era otra cosa que el despliegue lógico de lo que Rilke había expresado en forma poética" (Angelloz 1936, p. 3; en: Bollnow 1963, pp. 29-30); cabe señalar que Rilke no hace mención expresa del término 'modernidad'. Tampoco hace referencia a un 'problema de la modernidad'. Sin embargo, su diagnóstico acerca del hombre es coincidente con el de Heidegger: este se encuentra en un estado de desarraigo y destierro, que surge de la misma condición humana, manifestándose desde los comienzos de su vida en la tierra -en distintos grados-, y ahora con más fuerza debido al advenimiento de la técnica. Ambos proponen que ha de realizar un trabajo sobre sí mismo para comenzar a ser plenamente.

Las elegías del Duino y los Sonetos a Orfeo contienen una vasta descripción acerca de la precariedad de la situación existencial del hombre, que comprende la nostalgia de la patria, de los dioses y del ángel. Esta se inicia con una exposición de algunos elementos propios de la cultura moderna y luego continúa con la indagación acerca de la causa de la dificultad humana para instalarse con seguridad y confianza en el mundo. El poeta identifica la existencia de una "falla ancestral", consistente en un quiebre presente en la conciencia, que se manifiesta a través del sufrimiento.

Un primer elemento se encuentra en el Soneto $I I / X$, sobre la alienación que supone que la máquina reemplace el trabajo de las manos: "La máquina amenaza todo lo adquirido, si es que osa / instalarse en el espíritu en lugar de hacerlo en la obediencia. / Para que no se luzca el vacilar, más bello, de la espléndida mano, / corta ella firme la 
piedra para la construcción más resuelta. (...)” (Rilke 2002, p. 113). La técnica no solo atenta contra la tradición y las costumbres humanas contenidas en la práctica de oficios como la artesanía y la orfebrería, cuyo aprendizaje es experiencial, sino que amenaza con extinguir también la creatividad del hombre si no se le da el uso instrumental que le corresponde. Pero astutamente, la máquina asume un rol en la existencia, con la determinación y fuerza que nosotros no hemos podido ejercer: "Las construcciones informes de la producción técnica se interponen ante lo abierto de la pura percepción. Las cosas que fueron creciendo anteriormente desaparecen a toda velocidad" (Heidegger, p. 216). Esta amenaza de 'todo lo adquirido', implica la destrucción del arraigo que hizo posible la vida de nuestros ancestros.

A continuación, el siguiente extracto de la Elegía X, que contiene la descripción de la Ciudad de la Aflicción que un joven muerto debe atravesar antes de entrar plenamente en lo real, es particularmente ilustrativo del estilo de vida 'moderno' y sus distracciones, que mantienen desviada nuestra mirada: "Por cierto, ay, qué extrañas son las calles de la Ciudad de la Aflicción, / donde en el falso silencio, hecho de acallamiento, / se vanagloria, violento, lo vertido en el molde vacío: / el ruido dorado, el monumento que estalla. / Oh, cómo un ángel, sin dejar rastros, les pisotearía el mercado / del consuelo que la iglesia delimita, su iglesia comprada hecha: / limpia, cerrada y sin ilusiones, como una oficina de correos en domingo. / (...) / pero en especial para los adultos es visible cómo el dinero / se multiplica anatómicamente y no sólo para la diversión: / el órgano sexual del dinero, todo, el conjunto, el proceso; /...... Oh, pero justo más allá de eso, / tras el último tabique, empapelado con carteles de "La Sin Muerte", / aquella cerveza amarga que parece dulce a quienes la beben / cuando mastican además distracciones frescas..., / justo en el dorso del tabique, justo detrás, está lo real" (Rilke 2001, pp. 158-159).

Sin embargo, el poeta busca encontrar la verdadera causa de la tendencia humana a ocultarse de sí mismo y dar la espalda a la muerte. Esto lo lleva a indagar en la tradición judeo-cristiana y a reconocer en el episodio del asesinato de Abel, relatado en el Libro del Génesis (4:1-12), el 'hito inaugural' del conflicto. Rilke relata e interpreta este pasaje en el Libro de horas: "En tu palabra lo interpreto / desde la historia de los gestos / (...) / Con voz fuerte vivir, en voz baja morir / dijiste; y repetías siempre: ser. / Pero un asesinato se anticipó a la muerte. / (...) / Y desde aquel momento, lo que balbuceaban / son solamente trozos / del nombre tuyo antiguo. / Dice el pálido joven Abel: / Yo no existo. Algo me ha hecho el hermano / que no han visto mis ojos. / Me ha eclipsado la luz, / desplazando mi rostro / con el suyo" (2005, pp. 29-31). Abel sufre porque ha entrado en la muerte sin tener conocimiento de ello, de lo cual se deduce que el origen del problema humano está en la inconsciencia respecto de la propia muerte. Abel ha perdido la capacidad de verse a sí mismo, como si sus ojos hubieran sido velados. No puede comprender dónde está: al desconocer su propia muerte no es capaz de re-conocer su existencia.

Esta incapacidad nuestra de ver es mencionada ampliamente en la Elegía VIII: "Con todos sus ojos ve la criatura / lo abierto. Sólo nuestros ojos están / como invertidos y rodeándola a ella por completo / cual trampas en torno a su libre salida" (Rilke 
2001, p. 129) ${ }^{5}$. El hombre, a diferencia del animal y del niño -que aún no adquiere el conocimiento de la temporalidad-, no es capaz de mirar hacia 'lo abierto', hacia aquello que "sabe infinitamente y no desea" (Ibid.), y vive como si el hecho de morir fuera una contrariedad. "Siempre orientados hacia la creación, sólo vemos / sobre ésta el reflejo de lo libre, / oscurecido por nosotros. O que un animal, / uno mudo, alce la vista tranquilamente traspasándonos. / Esto se llama destino: estar frente a frente / y nada más, siempre frente a frente. / (...) / Y nosotros: espectadores, siempre, en todas partes, / vueltos hacia el todo y ¡nunca hacia afuera! / El todo nos desborda. Lo ordenamos. Se desintegra. / Lo volvemos a ordenar y nos desintegramos nosotros mismos" (Ibid., pp. 129-133).

Walter Falk, en relación al momento en que se instala este 'error' en la mirada, explica que "desde entonces el hombre miró en dirección contraria a lo abierto, miró 'hacia atrás'. Al verse como un ser único, como un individuo delimitado a consecuencia del reflejo de su propia visión, contempló todo el cosmos a la medida de su individuación. Contempló cada ente como algo segregado del uni-verso. El hombre trasplantó al cosmos su propia estructura fundamental de apartamiento" (1963, pp. 55-56). Esta hipótesis acerca del origen del problema existencial es acorde a la concepción antropológica rilkiana, donde la dificultad humana de 'ver' se relaciona más con una configuración interna que podríamos llamar defectuosa - una falla en el contorno del sentir-, que con una sumatoria de acontecimientos ocurridos en determinados momentos de la historia. "Rilke opinaba que la constitución fundamental de la existencia humana no habría sido nunca conocida en su realidad. Por eso, jamás se había planteado el problema de cómo poder vivir en consonancia con esa constitución fundamental, y por tanto no se había obtenido una solución - ¿quién ha respondido alguna vez?' (Rilke 1950, p. 52)”. (Falk, p. 58). “(...) Pues nosotros, donde sentimos, nos evaporamos, ay, / y luego espiramos y nos desvanecemos; de brasa en brasa / se debilita nuestro olor” (Rilke 2001, pp. 43-45).

La alusión que hace Rilke al episodio del Génesis para explicar la causa de la escisión de conciencia característica del hombre corresponde a una representación simbólica de aquello que Jacinto Choza describe como: “[u]na escisión de base estructural, una falla en la estructura de la síntesis entre el yo finito y la conciencia infinita, debida a la infinitud potencial de la conciencia. Infinitud potencial quiere decir que la conciencia oscila entre la finitud del yo y la infinitud del intelecto. (...) La falla abierta entre el yo y el sentido, la debilidad de la síntesis entre el sujeto y el logos, se debe, pues, a la temporalidad" (1991, pp. 46-47).

Otra consecuencia de esta 'falla estructural' es la lejanía del ángel, quien representa la posibilidad de existencia de un mundo trascendente a la materia y a la forma, con el cual podríamos relacionarnos. Gadamer señala: "Rilke los llama 'garantes de lo invisible' (...) El ángel es, en realidad, sólo la conciencia de la imposibilidad de darnos alcance a nosotros mismos, ya que somos seres 'metafísicos' que nos trascendemos.

Heidegger define el concepto de lo abierto como "la gran totalidad de todo aquello que no tiene límite" (Heidegger 1980, p. 280; en: Rilke 2001, p. 134). 
Y, sin embargo, ni siquiera el ángel nos oye” (p. 74). “¿Quién, si yo gritase, me oiría desde los coros / de los ángeles? Y aun suponiendo que alguno de ellos / me acogiera de pronto en su corazón, yo desaparecería / ante su existencia más poderosa" (Rilke 2001, p. 29). Es verdadera nostalgia de la relación con lo trascendente lo que expresa el hablante al comienzo de la Elegía II: "Todo ángel es terrible. Y, sin embargo, ay de mí, / sabiendo como sois, yo os canto, aves casi mortíferas del alma. / Adónde se han ido los días de Tobías, /cuando uno de los ángeles más deslumbrantes, / de pie junto a la sencilla puerta de la casa, / y algo disfrazado para el viaje, dejó de ser terrible; / (...) / Pero si en este momento el arcángel, el peligroso, / diese un solo paso hacia nosotros desde más allá de las estrellas, / el propio corazón, sobresaltado, nos destruiría. ¿Quiénes sois?" (Ibid., p. 43).

La dificultad de ver al ángel obedece a un error en la capacidad de mirar, en primera instancia, pero su génesis ocurre en un plano más íntimo y subjetivo: en el

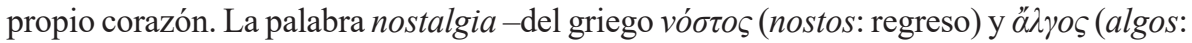
dolor $)^{6}$ - alude a algo que se recuerda con dolor, que se tuvo y se ha perdido: “(...) Pero cuando aludimos a una cosa, totalmente, / ya nos es perceptible el derroche de la otra. La enemistad / es lo más próximo a nosotros. (...) / porque se es muy claro con nosotros. No conocemos / el contorno del sentir: sólo aquello que lo forma desde fuera. / ¿Quién no se sentó temeroso ante el telón de su propio corazón? / Éste se abrió: el escenario fue una despedida" (Rilke 2001, p. 71). La falla estructural tiene como consecuencia el olvido de la realidad trascendente $y$, a la vez, la dificultad para sentir de manera plena aquello que captamos con nuestros sentidos. Nosotros 'no concordamos' (Ibid.) con la naturaleza, estamos incomunicados y somos 'sobrepasados y tardíos' (Ibid.). Es un problema de compás, de armonía. A diferencia de los animales y de las plantas, el hombre no vive incorporado al ritmo natural de todo lo viviente, donde la muerte es parte de un proceso que conforma la vida: "Desde hace ya mucho tiempo, higuera, me importa / cómo omites casi del todo la flor / y cómo introduces tu puro misterio, sin gloria, / al interior del fruto tempranamente decidido. (...) / ...... Nosotros, en cambio, nos demoramos, / ay, nos vanagloria el florecer y, traicionados, penetramos / al interior tardío de nuestro fruto perecedero" (Ibid., p. 103). Esta incapacidad de integrarnos en el todo circundante es consecuencia de la alienación del hombre en relación a su propio cuerpo, manifestación de su rechazo hacia su condición temporal: es el cuerpo, en su integración con la conciencia, lo que nos permite conocer el 'contorno del sentir'.

El siguiente extracto de la Elegía $X$ es particularmente representativo, expresado por una vieja Lamentación -un espíritu que habita el mundo de los muertos- que conduce a un joven difunto por el País de las Lamentaciones: “(...) Nosotras, / dice, éramos antaño un gran linaje (...) / Los padres ejercían la minería allá en las grandes montañas; entre los / hombres tú encuentras a veces un trozo tallado de sufrimiento / originario o la ira de un viejo volcán petrificada en forma de escoria. / Sí, de allá

6 Entrada: Nostalgia. En Diccionario Etimológico de Chile, disponible en: http://etimologias. dechile.net/?nostalgia. 
provenía todo esto. En otro tiempo fuimos ricas. / (...) / Le muestra los altos árboles de las lágrimas y los campos de floreciente nostalgia (los vivos los conocen sólo como suave follaje) / (...). / En la tarde lo lleva a las tumbas de los ancianos / del linaje de las Lamentaciones, de las sibilas y agoreros" (Ibid., pp. 159-161). En las palabras de la Lamentación reconocemos un vínculo entre el sentir humano y la naturaleza, como si esta recogiera todo aquello que experimentamos en vida. El poeta otorga un lugar fundamental al sufrimiento y a las emociones 'difíciles' al interior del país de la muerte, pues estas conforman árboles, campos y montañas, elementos centrales del paisaje que recorre el joven difunto; otorgándoles un sentido trascendente: “( ....... Ah, y con respecto a la otra relación, / ay, ¿qué se lleva uno hacia el más allá? No el mirar, aquí / lentamente aprendido, y nada de lo que aquí ocurrió. Nada. / Pero sí los dolores. Sobre todo la pesadumbre, también la larga experiencia del amor: es decir, / todo lo inefable" (Ibid., pp. 143-145).

El lugar de la muerte se conforma de todo aquello que experimentamos y 'eternizamos' a través de su aceptación consciente. Pero la muerte ya no es 'un gran linaje', pues hemos perdido también la capacidad de sentir plenamente en el plano emocional. Al señalar que el dolor es parte de lo que nos llevamos al 'más allá', el poeta devela una relación entre el sufrimiento y la muerte: la aceptación del primero se presenta como una vía para el reconocimiento -y construcción- de la segunda. Utiliza la imagen de la naturaleza para representar esta relación, pues de ella debemos aprender una nueva disposición: "Tierra, tú amada, yo quiero. Oh créeme, ya no son necesarias / tus primaveras para que me conquistes: una, / ay, una sola ya es demasiado para la sangre. / Estoy, sin nombre y desde lejos, decidido por ti. / Siempre tuviste la razón y tu más santa ocurrencia / ha sido la muerte amistosa" (Ibid., p. 147).

\section{II.3.- Propuesta del poeta: La trascendencia de la muerte}

\section{II.3.1.- La misión del hombre y el canto de Orfeo}

Rilke sitúa en Orfeo la imagen de perfección a la cual debiera aspirar el hombre, pues su canto es existencia. Proveniente de un corazón que ha conocido el mundo de los muertos y que ha trascendido el dolor de la pérdida, su voz se eleva en busca de la trascendencia del amor: “¿Es él de aquí? No, desde ambos / reinos creció su naturaleza vasta. / Quien sepa de las raíces del sauce / será más apto para doblar sus ramas. (...) / Nada le puede empañar su imagen valedera; / y ya sea desde tumbas o desde habitaciones, / celebre él anillo, prendedor y cántaro" (Rilke 2002, p. 27). Su canto confiere trascendencia a cuanto nombra y a aquello que escucha el sonido de su voz, incorporándolo al ámbito de lo sagrado: "Ahí se elevó un árbol. ¡Oh pura trascendencia! / ¡Oh, Orfeo canta! ¡Oh, árbol alto en el oído!” (Ibid., p. 23); y es una celebración de la realidad, ya que al nombrar las diversas cosas que conforman el mundo hace una reafirmación de la vida, instaurando un nuevo orden existencial, donde no existe la muerte como término, sino como transformación y como forma de redención de la materia.

El canto de Orfeo es una invitación para iniciar el proceso de restauración de la unidad de la propia conciencia. El poeta plantea como misión del hombre la de aprender 
a ser: "(...) No se ha reconocido el dolor / ni se ha aprendido el amor / y lo que nos aleja en la muerte / no ha sido develado aún. / Sólo el canto sobre la tierra / santifica y celebra" (Ibid., p. 41). El logro de estas tres tareas otorgaría al ser humano el grado de ser, por el trabajo individual y el aprendizaje que requieren para su concreción. Sin embargo, estas sugerencias pueden reunirse en una: aceptar y trascender la muerte.

En el mensaje rilkiano es posible identificar diversas recomendaciones para realizar dicho propósito, que abarcan tanto la relación con el mundo circundante como el desarrollo de la propia individualidad:

\section{a) Relación con el mundo circundante: cantar la naturaleza y las cosas}

Una primera recomendación la encontramos en la Elegía VII, donde el poeta se refiere a la 'conservación de la forma aún reconocida', en un intento por recoger aquello que la modernidad aún no ha arrebatado de las manos del hombre, valorando la experiencia humana por sobre la novedad de la técnica y del modo de vida que propone: “(...) Cada giro apagado del mundo deja tales desheredados, / a quienes no les pertenece lo anterior ni todavía lo próximo. / Porque también lo próximo es distante para los humanos. / Esto no debe confundirnos, sino fortalecer en nosotros / la conservación de la forma aún reconocida. Esto estuvo una vez / entre los hombres, estuvo en medio del destino destructor, / (...) Ángel, a ti te lo muestro todavía, / ¡ahí! En tu mirar se yergue por fin ahora redimido. / Columnas, pórticos, la ambiciosa resistencia de la esfinge y / de la catedral gris que emerge de la ciudad transitoria o ajena" (Rilke 2001, pp. 115-117). Al considerar el conjunto de objetos, tradiciones y costumbres humanas conservadas hasta hoy y presentárselas al ángel, les damos significación de eternidad. Cuando el ángel las 'toma', las integra al universo. Sin embargo, es en nuestro interior donde las cosas adquieren infinitud, dependiendo de la valoración que les otorguemos: “(...) Queremos alzarla para que se vea, / cuando en realidad la felicidad más evidente / recién se nos revela si en el interior la transformamos. / En ningún sitio, amada, habrá mundo si no es dentro. Nuestra vida / transcurre con transformaciones. Y lo externo, siempre más insignificante, se desvanece" (Ibid., p. 115).

El poeta nos insta a decir las cosas para 'salvarlas de la muerte': nombrarlas con la palabra, reconociendo su significado en nuestras vidas, devolviéndoles su vínculo con lo humano: "Estamos aquí tal vez para decir: casa, / puente, manantial, portón, cántaro, árbol frutal, ventana, / o a lo más: columna, torre... pero para decir, compréndelo, / oh, para decir de una manera tal, como las cosas mismas jamás / pensaron ser en su intimidad. ¿No es una secreta astucia / la de esta tierra callada, cuando ella urge a los amantes / para que a través de su sentimiento se encante toda y cada cosa? (...)/ Aquí está el tiempo de lo decible, aquí su patria" (Ibid., p. 145).

El valor conferido a las cosas estriba en que, a partir de su vínculo con ellas, el hombre puede restablecer su relación 'originaria' con la tierra y, por extensión, con su propio cuerpo: "La naturaleza, las cosas de nuestro uso cotidiano son, por cierto, provisionales y caducas, pero son, mientras estamos aquí en la tierra, nuestra propiedad y nuestra amistad; ellas son consabidoras de nuestra alegría y de nuestra miseria y ya fueron las confidentes de nuestros antepasados. Así, no sólo no hay que descalificar y 
degradar lo de aquí, sino que precisamente por su provisionalidad, que comparten con nosotros, estas apariencias y estas cosas tienen que ser comprendidas y transformadas por nosotros por medio del entendimiento más entrañable... ¿Transformadas? Sí, porque nuestra tarea es ésta: impregnarnos de esta tierra provisional y caduca tan profundamente, tan dolientemente, tan apasionadamente, que su esencia resurja otra vez en nosotros, invisible. Somos las abejas de lo invisible..." (Rilke 1925, en: Rilke 2001, p. 25). Nombrar cada cosa 'consabidora de nosotros', permitiendo que resuene en el espacio la vibración del sonido producido por la voz que contiene su nombre, otorgaría a estas cosas un nuevo modo de ser, como si al ser nombradas desde un genuino reconocimiento de su valor, recuperaran su capacidad de ser reales.

\section{b) Relación con la propia individualidad: conciencia del cuerpo}

La propuesta de Rilke considera la materia como el punto de partida para el proceso de trascendencia: el sustrato de la transformación. "La temporalidad que hay que llenar es la del yo (es la propia vida, la duración de la propia existencia), no la del intelecto, pues el intelecto, debido precisamente a su infinitud, no tiene, de suyo, una temporalidad determinada y finita que no sea la del yo. (...) Lo que cabe es vivir; la paciencia, la esperanza, o lo que es lo mismo, lo arduo: vivir en el tiempo y en la eternidad a la vez" (Choza, pp. 47-48). A partir de la vivencia de la caducidad es posible comenzar a estrechar la distancia entre finito e infinito. Esto se debe a que los cambios que repercutirán en el plano trascendente de un ser son posibles gracias a la 'plasticidad' de la materia: solo desde lo sensible es posible afectar lo espiritual. El conocimiento de esta posibilidad es -aunque no tengamos plena conciencia de ello-, el único verdadero reparo del hombre frente a la muerte: “¿Por qué cuando es posible cumplir el plazo de la existencia / como el laurel, algo más oscuro que todo otro verde, / con pequeñas ondulaciones en el borde de cada hoja / (como la sonrisa del viento): por qué entonces forzar lo humano y, evitando el destino, / anhelar destino?... / Oh, no porque haya felicidad, / este privilegio anticipado de una pérdida cercana. / (...) Pero sí porque el estar aquí es mucho y porque en apariencia / todo lo aquende, eso que se desvanece, nos necesita y / extrañamente nos concierne. A nosotros, a los más fugitivos. / Una vez cada cosa, sólo una vez. Una vez y no más. / Y nosotros también una vez. Nunca más. Pero / haber sido esa una vez, aunque sólo sea una vez, / este haber sido terrenal: eso parece irrevocable. (...) / Lo que más quisiéramos / es conservarlo todo para siempre..." (Rilke 2001, p. 143).

Cabe mencionar que esta consideración acerca de la materia corresponde a un principio perteneciente a la filosofía budista, y también al cristianismo originario -lo que da cuenta de una influencia plurirreligiosa en Rilke-. Las siguientes palabras de Sri Aurobindo son especialmente aclaradoras respecto de la tarea humana: "Porque la gravosa herencia animal y humana que pesa en nuestro subconsciente y que se transmite automáticamente por nuestra concepción material, es uno de los más difíciles obstáculos de la transformación (...) Nos hallamos aquí en presencia de los dos problemas fundamentales del aspirante: dar a las células del cuerpo la conciencia de 
inmortalidad que ya existe en nuestra alma, y aun en nuestra mente, y depurar de todo punto el subconsciente" (Satprem 1989, p. 175).

\section{II.3.2. Ascética rilkiana}

El término ascética refiere a un conjunto de prácticas orientadas a lograr el fortalecimiento del espíritu y el perfeccionamiento individual (Ferrater, p. 145). Hemos llamado 'ascética rilkeana' al proceso de autoconocimiento a través de la conciencia del cuerpo, descrito por el poeta, mediante el cual plantea que todo lo que se experimenta en él, contiene un significado o un sentido definido, como si conformara a una forma de lenguaje proveniente de nuestra 'parte' infinita. Nuestras emociones ${ }^{7}$ nos dicen quiénes somos, en la medida que nos señalan aquello que nos agrada y aquello que rechazamos espontáneamente, de tal modo que su aceptación consciente constituye una ruta inequívoca conducente a la re-unión de nuestra naturaleza. La reflexión acerca del origen de estas sensaciones, nos dará la pauta para reconocer en nosotros determinadas características del propio ser e individualidad, pues la ponderación interna acerca de lo que experimentamos da a estas vivencias la categoría de ser 'objetos de intelección': sometiéndolas al análisis de la razón, les otorgamos 'valor de realidad'.

Una primera recomendación la encontramos en Cartas a un joven poeta: "Pregunta usted si sus versos son buenos (...) Mira usted hacia fuera, y eso, sobre todo, no debería hacerlo ahora. Nadie puede aconsejarle ni ayudarle, nadie. Hay sólo un único medio. Entre en usted. Examine ese fundamento que usted llama escribir; ponga a prueba si extiende sus raíces hasta el lugar más profundo de su corazón (...)" (Rilke 2005, pp. 24-25). El poeta considera que la honestidad con uno mismo y la afirmación de lo más propio y genuino en cada uno es la única salida posible frente a la angustia y el desarraigo existencial, cuya causa es el desconocimiento de la propia identidad. El nuevo arraigo del hombre ha de realizarse desde el interior, a partir de un nuevo conocimiento de su esencia, el cual es potencialmente adquirible tanto desde el plano consciente como desde el inconsciente del individuo:

\section{a) Aceptar el sufrimiento: vivencia consciente de las mociones del cuerpo}

Las sugerencias realizadas por el poeta se centran, particularmente, en la aceptación consciente y voluntaria del dolor y el sufrimiento que experimentamos durante la vida, pues en ellos se encuentra el germen y la posibilidad de lograr la trascendencia, por el despojamiento que supone de los deseos personales; mientras nos conduce 'obligatoriamente' a la aceptación de la realidad: “está claro que nosotros debemos atenernos a lo difícil; todo lo vivo se atiene a ello, todo en la naturaleza crece y se defiende a su manera y es algo propio a partir de sí mismo" (Rilke 2015, p. 87). El trabajo de

Del latín emotio, emotionis, deriva del verbo emovere: movere (mover, trasladar), más el prefijo e-/ex (de, desde); significando retirar, hacer mover. Entrada: Emoción. En Diccionario Etimológico de Chile, disponible en: http://etimologias.dechile.net/?emocio.n 
ascesis rilkiano implica rebasar el deseo, obedecer, aceptar y trascender; no resistirse a aquello más arduo, doloroso y trabajoso que bulle en nuestra interioridad, pues esto nos conducirá progresivamente a nuestro destino, en la medida que lo atendamos: "Si nos fuera posible mirar más allá de lo que alcanza nuestro saber, incluso pasando un poco sobre las avanzadas de nuestro presentimiento, quizá soportaríamos entonces nuestras tristezas con mayor confianza que nuestro gozo. Pues ellas son los momentos en que ha entrado algo nuevo en nosotros, algo desconocido; nuestros sentires enmudecen en tímido cohibimiento, todo lo que hay en nosotros retrocede, surge un silencio, y lo nuevo, que nadie conoce, se yergue en medio y calla. (...) Estamos en medio de un tránsito donde no podemos quedarnos quietos. Por eso también pasa la tristeza: lo nuevo en nosotros, lo sobrevenido, ha entrado en nuestro corazón, ha penetrado en su más íntima estancia, y tampoco está ya ahí: ya está en la sangre” (Rilke 2005, p. 80).

El poeta aconseja prestar especial atención al sufrimiento relacionado con las experiencias del amor y la muerte. Pues para comprender la naturaleza del amor, es necesario comenzar por la aceptación del dolor que conlleva la soledad, en su primera etapa. Solo quien se posea a sí mismo, será capaz de amar verdaderamente, y no 'utilizará' al otro para desviar su mirada y ocultarse de sí: “(...) si te abruma la nostalgia, canta a los amantes; mucho falta todavía / para que su célebre sentimiento sea lo bastante inmortal. / Y a esos abandonados que tú casi envidias y a quienes encontraste / aún más capaces de amar que a los satisfechos (...)." (Rilke 2001, p. 31). Además, el aprendizaje del amor supone la aceptación serena de la despedida, inevitable en una relación entre seres finitos: “¿Has pensado bastante / en Gaspara Stampa ${ }^{8}$, para que así alguna muchacha / a quién dejó su amado, ante el ejemplo señero de esta amante, / sienta: y si yo llegase a ser como ella? / ¿No deberían, al fin, hacérsenos más fecundos estos viejos dolores? / ¿No es tiempo ya de liberarnos, amando, del amado / y de resistir estremecidos, como resiste la flecha a la cuerda, / para ser, concentrada en el salto, más que ella misma? / Porque no hay permanecer en parte alguna" (Ibid., p. 31).

Una nueva mirada acerca de todo aquello que es arduo y difícil, es el medio que tenemos a nuestro alcance para comenzar a 'construir' nuestra propia muerte, en cuanto dejamos de identificarnos progresivamente con el propio cuerpo, propiciando la formación de una conciencia del yo con independencia del mismo. En relación con esto, Gadamer comenta que "La prometida superación de la muerte no consiste en ocultar su amargura, sino en aceptar el supremo abandono de sí mismo del que Cristo dio ejemplo. Ese es el auténtico mensaje del cristianismo y no la sentimental esperanza ultraterrena en un cielo de reencuentros y en la recompensa de la fe por todas las penalidades sufridas" (pp. 72-73).

8 "Gaspara Stampa (1523-1554) es una poetisa italiana, nacida en Padua, que en sus poemas cantó su amor no correspondido por el noble veneciano Collatino di Collalto" (Rilke 2001, p. 34). 


\section{b) A través del sueño y la sexualidad: conocimiento del inconsciente}

Una segunda vía para incorporar a la conciencia las vivencias del cuerpo, la encontramos en la Tercera Elegía, donde el poeta describe el proceso mediante el cual, al dormirnos, accedemos progresivamente a la realidad invisible que subyace en nuestro inconsciente, de la cual algo conocemos a través de los sueños. Aquí se encuentra la memoria de nuestros antepasados, de modo que, al reconocerlos en nosotros, estaríamos 'superando' el propio nacimiento. Atender a este proceso e introducirse en él de modo más o menos voluntario, nos permitiría comprender el sustrato de las emociones que solemos identificar como propias, depurando de la identidad aquello que no es genuino: “(...) Y él mismo, cómo yacía, el aliviado, bajo sus / párpados soñolientos y disolviendo el dulzor de tu leve figura / en esos saboreados momentos previos al sueño; / si parecía un protegido... Pero por dentro: ¿quién rechazaba, / quién impedía en su interior los torrentes del origen? / Ay, entonces no había ninguna precaución en el durmiente; / durmiendo, pero soñando, pero febril: cómo se entregaba. (...) / Amaba. Amaba su interioridad, su naturaleza salvaje, / esa selva dentro de él, sobre cuyo mudo estar caído / se irguió su corazón en verde claro. Amaba. Y lo abandonó, / siguiendo las propias raíces hacia el origen poderoso, / donde su modesto nacimiento había sido ya sobrevivido" (Rilke 2001, p. 59). Es su origen quien ejerce un poderoso y seductor llamado sobre él, probablemente, por contener la 'llave' de la liberación de su finitud.

Sin embargo, a continuación, la descripción toma un giro inesperado, donde el amor del niño -que ahora pasa a ser, deliberadamente, un joven-, hacia su naturaleza salvaje, se confunde con el amor sexual que experimenta en relación a la muchacha. La Elegía continúa relatando que el joven, al amar, 'descendía hacia la sangre más antigua', expresando una vinculación entre el sueño, el deseo y la sangre: “(...) Amando descendía hacia la sangre más antigua, hasta los barrancos / donde yacía lo temible, aún saturado de los padres. Y todo lo terrible / lo conocía, le hacía guiños, como si estuviese al tanto. / Más aún, lo espantoso sonreía... (...) / Mira, nosotros no amamos, como las flores, desde un / solo año; nos sube por los brazos, cuando amamos, / una savia inmemorial. Oh muchacha, / esto: amábamos en nosotros, no una cosa, algo venidero, (...) / sino a los padres, que como ruinas de montañas / reposan en el fondo de nosotros; sino el cauce seco / de madres remotas; (...) / todo esto, muchacha, se te anticipó" (Ibid., pp. 59-61). A través del acto sexual es posible acceder a la memoria ancestral contenida en la sangre: 'nos sube por los brazos, cuando amamos, / una savia inmemorial'. Y en aquellos 'barrancos/ donde yacía lo temible, aún saturado de los padres', el joven experimenta amor frente a 'lo terrible' y 'lo espantoso', que le 'sonreía', 'como si estuviese al tanto (como si lo conociera). En este pasaje, resulta evidente la presencia de más de un elemento perteneciente a la teoría freudiana ${ }^{9}$ del inconsciente, como el concepto

9 Es probable que el poeta, por medio de su amistad con Lou Andreas-Salomé (San Petersburgo, 1861 - Gotinga, 1937), escritora y filósofa rusa, quien fue parte del círculo de más fieles seguidores de Freud, haya conocido las investigaciones y postulados del maestro vienés (Dörr 2007, pp. 24-30). 
de 'lo siniestro', 'Das Unheimlich': "lo siniestro sería aquella suerte de espantoso que afecta las cosas conocidas y familiares desde tiempo atrás. (...) No sería realmente nada nuevo, sino más bien algo que siempre fue familiar a la vida psíquica y que sólo se tornó extraño mediante el proceso de su represión. (...) Siniestro es todo aquello que, habiendo sido propio y luego olvidado, retorna a la conciencia como algo lejano, desconocido y, por tanto, amenazante" (Freud 1978, pp. 48-86). El joven, al amar 'lo ominoso' revela haber tenido con ello una antigua relación que, debido al olvido, se transformó en miedo y angustia; y que, al recordarla, dejó de ser terrible. Al reconocer y aceptar su complicidad con esto, supera o trasciende sus temores y, además, la figura de la madre, en cuanto experimenta respecto de aquel una cercanía anterior a la de ella: "Antes de ti él ya lo amaba, / porque cuando lo llevabas en tu vientre/ estaba disuelto en el agua, la que aliviana al que germina" (Rilke 2001, p. 59).

Este vínculo particular y antiguo entre ‘lo siniestro’ y el joven revela, en parte, el origen del conflicto anteriormente descrito sobre la falla estructural del hombre: no podemos ver la propia muerte, porque desconocemos nuestras raíces, que reposan en el fondo de nuestro inconsciente y que se manifiestan en la conciencia a través de miedos; pues tememos a aquello que más intensamente deseamos. La seducción que ejercen 'los torrentes del origen' sobre el joven, obedece a que en ellos está contenida parte de la información referente a la propia identidad necesaria para unificar la conciencia. $\mathrm{Al}$ amar, trascendemos la propia individualidad, pues 'amamos' aquello que 'fermenta incontablemente': todos los niños, todos los padres y todo el paisaje, de todos los tiempos y de cada lugar; es decir, aquello que coexiste en nuestra memoria celular por encima de la temporalidad. Esto implica, en cierta medida, la afirmación de la existencia de una memoria colectiva contenida en el inconsciente, a la cual accederíamos cuando se diluyen los límites de tiempo y espacio que se definen a partir de la materialidad. Ahora bien, si la memoria contenida en el inconsciente colectivo coincide con nuestro origen remoto, entonces debemos concluir que aquella 'identidad' personal que buscamos, se encuentra donde los límites del yo finito se han disuelto: “(...) Permanece siempre muerto junto a Eurídice; con más cantos / y alabanzas regresa ascendiendo a la pura relación. (...) / Sé la razón infinita de tu vibración más íntima, / de modo que la realices por completo esta única vez / y conoce al mismo tiempo la condición del no-ser. / A las reservas de la naturaleza plena, tanto a las usadas / como a las sordas y a las mudas, a las sumas indecibles, / incorpórate jubiloso y destruye el número" (Rilke 2002, p. 117).

El desafío es adelantarse a la propia muerte: "se tú un cristal sonoro que ya se quebró al sonar" (Ibid.), entrar en ella de modo consciente y voluntario, siendo causa de la propia trascendencia. Así, al acompasarnos con la naturaleza y su ritmo, recuperaremos la capacidad de percibir lo real.

\section{II.3.3. Concepto de Dios en Rilke}

Son pocas las ocasiones en que el poeta alude 'directamente' a la figura de un Dios en las obras estudiadas pues, generalmente, las representaciones de lo divino están encarnadas en los personajes de Orfeo y el ángel. Sin embargo, aun cuando dichas menciones sean 
escasas, es posible reconocer una noción rilkeana de divinidad, al relacionarlas con lo que el poeta mismo explica en algunas de sus obras en prosa.

El hombre, al comenzar a vivir humanamente en la tierra, por medio del aprendizaje del amor, la muerte y el dolor, contribuye también a la formación de la existencia de los demás hombres, a los que está unido por la especie, disponiendo el mundo para un nuevo habitar. El logro supremo de esta tarea coincidiría con la 'maduración' de 'Dios' dentro de cada uno. El poeta asegura que toda la creación trabaja para esto - consciente o inconscientemente-. La naturaleza ya está lista, sin embargo, tanto ella como el ángel necesitan del humano para que, al cantarla y nombrarla, se haga nuevamente real y pueda ser parte de este Dios que nacerá del hombre para vivir en su mundo, junto a él a y a sus cosas, cuya sustancia estará conformada por todo aquello que haya logrado transformar en invisible: "Dios como el fruto maduro de un árbol cuyas hojas somos nosotros (...) ¿No debe ser Él, el Último, a fin de abarcarlo todo en sí? ¿Y qué sentido tendría nuestra búsqueda si Aquel a quien anhelamos ya hubiese existido? (...) hasta con lo menudo, con lo insignificante (siempre que sea por amor) le damos comienzo; en el trabajo, después con el reposo; con el silencio o con una efímera y solitaria alegría; con todo cuanto hacemos solos, sin ayuda ni seguidores, comenzamos a Aquel que no llegaremos a ver, así como nuestros antepasados tampoco pudieron vernos. (...) ¿Hay algo que pueda sustraerle a usted la esperanza de ser así, algún día, en él, el más lejano, el Supremo?" (Rilke 2005, pp. 98-99).

La idea rilkeana de Dios representa lo eterno: aquello que el animal conoce al no temer su muerte, lo abierto o lo no formado, el espacio puro. Se encuentra en el lugar del allende, junto al espíritu que conduce al joven muerto por el 'País de las Lamentaciones', conformado por los sufrimientos y alegrías experimentados por los hombres durante su peregrinar terreno. Es, por tanto, una divinidad que subyace en los cimientos de la naturaleza y de nuestro propio sentir: el fundamento de todo lo que existe. El regreso a 'nuestro origen remoto', coincidente con la integración del propio yo a las 'sumas indecibles de la naturaleza', equivale al nacimiento de este nuevo Dios, contenedor de todo lo real, cuyo surgimiento dependerá de la comprensión que logre tener el hombre acerca de sí mismo, conformando un arraigo para su existencia. De este modo, el concepto rilkiano de Dios, inscrito en el registro invisible de la realidad, constituye una solución a la penuria de los tiempos, dado que el aprendizaje de serhombre coincide con el conocimiento y materialización de la divinidad. "“Esto es lo que ocurre. La gente siempre aparta la vista de Dios. Lo buscan arriba en la luz, que se torna cada / vez más fría y punzante'. (...) / 'Y Dios espera en otra parte...espera... en el fondo del Todo. Profundamente. / Donde están las raíces. Donde hay, oscuridad y tibieza'. (...) / ‘ ¿Tener... miedo? (...) ¿De qué?” (Rilke 1945, p. 112).

\section{III. - Conclusiones}

La propuesta de Rilke tiene el valor de poner en las manos del hombre la capacidad de resolver su conflicto existencial, sin necesidad de recurrir a una ayuda sobrenatural o a un cambio histórico: este, si ocurriera, sería a causa de la transformación individual 
de cada uno. Es una apuesta por el encuentro y manifestación de la divinidad interior, con la consecuente adquisición de la inmortalidad. En este punto, resulta evidente la resonancia entre la cosmovisión rilkiana y el pensamiento de Nietzsche, principalmente por el valor concedido a la voluntad como fundamental agente de cambio: "para ambos la actividad más propia y específica del espíritu humano es crear mundos dotando de significado y de valor a las realidades con las que uno se encuentra" (Choza, pp. 42-43).

Intuitivo y plurireligioso, Rilke no es encasillable en una filosofía o religión específica. Al proponer una nueva relación del hombre con el cosmos, cuestiona nuestra tradicional noción de 'infinitud' y de 'trascendencia', acercándose más a un entendimiento "cuántico" de la realidad, donde el límite entre lo visible y lo invisible está dado por el determinado nivel de conciencia que cada uno tenga acerca de sí mismo y de la realidad: "Y lo nuestro se desprende de nosotros, como el rocío de la hierba temprana / o el calor de una comida caliente. Oh sonrisa, ¿hacia dónde? / Oh mirada hacia lo alto. Nueva, cálida y esquiva onda del corazón; / ay de mí, eso sí somos nosotros. ¿Es que el espacio cósmico / en que nos diluimos tiene, entonces, sabor a nosotros?" (Rilke 2001, pp. 43-45).

A la luz de esta nueva mirada, Rilke demuestra que la muerte como término de la vida no existe, y que esta concepción es más bien un error de percepción debido a la dualidad de nuestra naturaleza. La muerte de un hombre consciente, unificado, corresponde a la continuación de algo cuya existencia comenzó con la decisión tomada de ser, expresada en la incorporación del propio sentir a la reflexión acerca del yo. “(...) Comprendemos perfectamente por qué puede llamarse a la muerte la 'sagrada inspiración' de la naturaleza: ella nos amonesta a ser completa y absolutamente conscientes del 'estar aquí"' (Gadamer, p. 78). Esta conciencia del 'estar aquí', nos permitirá desarrollar, poco a poco, una auténtica capacidad de amar. Quizás sea esta la razón más urgente por la que el poeta nos insta a realizar la aceptación de la muerte. Si bien ya no nos encontramos en los 'tiempos de penuria' que vivió Rilke-caracterizados por la crisis cultural occidental moderna-, somos herederos de su precariedad ontológica, descrita por Heidegger como "ausencia total de fundamento" (p. 200). La obra del poeta constituye un testimonio de la búsqueda de la unidad, un legado para todo aquel que, pese a la fuerza cegadora de la 'cultura material', se pregunte acerca de su origen, en un intento por conocer su identidad, más allá del propio nombre.

Visionario, las predicciones que realizó sobre la mujer y su transformación en la sociedad ya comenzaron a materializarse: "La muchacha y la mujer, en su despliegue nuevo y propio, serán sólo transitoriamente imitadoras de las maneras de ser y de no ser masculinas (...) sólo para depurar su modo de ser más propio de las influencias deformadoras del otro sexo. (...) Esta humanidad de la mujer, (...) saldrá a la luz cuando haya eliminado los convencionalismos de lo exclusivamente femenino en las transformaciones de su condición externa (...). Algún día (...) existirá la mujer cuyo nombre ya no signifique sólo lo contrario de lo masculino, sino algo en sí mismo: la persona femenina. / Este progreso (...) transformará la experiencia del amor, (...) en una relación que se entienda de persona a persona, y ya no de hombre a mujer" (Rilke 2015, pp. 97-99). 


\section{Referencias bibliográficas}

Bollnow, Otto F. (1963), Rilke. Traducción de Jaime Ferreiro Alemparte. Madrid: Taurus.

Choza, Jacinto (1991), Al otro lado de la muerte. Pamplona: Ediciones Universidad de Navarra.

Dörr, Otto (2007), “El destierro del poeta”, La palabra y la música. Santiago de Chile: Ediciones UDP.

Falk, Walter (1963), "Rainer Maria Rilke y la aflicción”, Impresionismo y Expresionismo. Madrid: Guadarrama.

Ferrater, José (1964), Diccionario de Filosofía. Quinta Edición. Tomos I - II. Buenos Aires: Sudamericana.

Freud, Sigmund (1978), "Lo ominoso", Obras Completas. Vol. XVII. Buenos Aires: Amorrortu.

Gadamer, Hans Georg (1993), "Rainer Maria Rilke, 50 años después”, Poema y diálogo. Ensayos sobre los poetas alemanes más significativos del siglo XX. Barcelona: Gedisa.

Heidegger, Martin (1996), “YY para qué poetas?”, Caminos de bosque. Traducción de Helena Cortés y Arturo Leyte. Madrid: Alianza.

Rilke, Rainer M. (2015), Cartas a un joven poeta. Traducción de Jesús Munárriz. Madrid: Hiperión.

(2005), Cartas a un joven poeta. Traducción de José María Valverde. Madrid: Alianza.

(2005), El libro de horas. Edición bilingüe. Traducción y notas de Federico Bermúdez Cañete. Madrid: Hiperión.

(2001), Las Elegías del Duino. Edición bilingüe. Traducción de Otto Dörr Zegers. Santiago de Chile: Universitaria.

(2002), Sonetos a Orfeo. Edición bilingüe. Traducción de Otto Dörr Zegers. Santiago de Chile: Universitaria. Calomino.

(1945), "Vladimiro, pintor de nubes", El rey Bohusch. La Plata:

Satprem (1989), Sri Aurobindo o La Aventura de la Conciencia. Traducción de Ricardo Barrios. Barcelona: Fundación Centro Sri Aurobindo.

Steiner, George (2012), La poesía del pensamiento. Del helenismo a Celan. Traducción del inglés de María Cóndor. Madrid: Siruela.

\section{Recursos electrónicos}

Diccionario etimológico de Chile. Disponible en: http://etimologias.dechile.net

Diccionario de la Real Academia Española. Vigésima Tercera Edición. Versión en línea, disponible en: http://www.rae.es 